\title{
The Relationship Between Carotid Intima Media Thickness, Inflammation and GLA Rich Protein Levels in Chronic Kidney Disease
}

\author{
Recep Demirci ${ }^{1, *}$ \\ Can Sevinc $\mathbb{D}^{2, *}$
}

'Department of Nephrology, University of Health Science, Kanuni Sultan Suleyman Research and Training Hospital, Istanbul, Turkey; ${ }^{2}$ Department of Nephrology, Ataturk University Faculty of Medicine, Erzurum, Turkey

*These authors contributed equally to this work
Correspondence: Can Sevinc Email can.sevinc@atauni.edu.tr

\begin{abstract}
Aim: Vascular calcification is a common complication in CKD. Studies conducted in patients with end-stage renal disease (ESRD) showed that calcification in vascular structures is an important component of the atherosclerosis process. GLA rich protein (GRP) has been suggested as a potential marker for vascular calcification. We investigated the relationship between GRP levels, carotid intima media thickness and inflammatory parameters in patients with predialysis stage 3, 4 and 5 CKD.
\end{abstract}

Material and Methods: A total of 106 patients aged $\geq 18$ years with CKD stage 3 , stage 4 and non-dialysis stage 5 and 25 healthy volunteers were enrolled in the study. Patients with obesity, uncontrolled hypertension, coronary artery disease, with active cancer or liver disease, malignant hematologic disorders, acute renal failure, acute or chronic infections were excluded. As the control group, healthy volunteers without any known illness, regular drug use, smoking, alcohol use, and obesity were recruited.

Results: Patients were divided into two groups as those with CIMT below $0.90 \mathrm{~mm}$ and those with CIMT $0.90 \mathrm{~mm}$ and above. There was no significant difference between the two groups in terms of the presence of HT and DM. While the CRP values of the group with high CIMT were found to be significantly higher $(\mathrm{p}=0.005)$, the GLA rich protein levels of this group were found to be significantly higher $(\mathrm{p}=0.019)$.

Conclusion: In our study, it was determined that there was a positive correlation between GRP levels and CIMT in patients with predialysis CKD, and GRP levels were higher in patients with CIMT above $0.90 \mathrm{~mm}$. These findings suggest that GRP levels can be used as a cardiovascular event biomarker in patients with CKD.

Keywords: chronic kidney disease, carotid intima media thickness, inflammation, GLA rich protein

\section{Introduction}

Chronic Kidney Disease (CKD) is a serious public health problem with high mortality and morbidity, increasing frequency due to increasing age and accompanying chronic diseases, and also having high costs. Cardiovascular and cerebrovascular diseases, which are frequently encountered in CKD, are the most important causes of mortality. It has been observed that traditional atherosclerosis risk factors such as age, hypertension (HT), diabetes mellitus (DM), lipid disorders, obesity, and tobacco smoking habits revealed in epidemiological studies such as the Framingham study cannot fully explain the early-rapidly developing atherosclerosis in CKD. In addition to traditional atherosclerosis risk factors, new risk factors associated with uremia are thought to play an important role in the development of 
early and rapidly progressive atherosclerosis in the CKD process. Identification and control of these new unconventional uremia-related risk factors may contribute significantly to reducing the risk of cardiovascular disease in these patients. $^{1,2}$

Vascular calcification is a common complication in CKD. It showed that the extent and type of vascular calcification are predictors of mortality. Although research over the past decade has greatly improved our knowledge of the numerous factors and mechanisms involved in vascular calcification in patients with kidney disease, many questions remain unanswered. The concept that vascular calcification in $\mathrm{CKD}$ is a passive process resulting from an increased calcium-phosphorus load is no longer accepted. As a result of the metabolic effects of diabetes, dyslipidemia, oxidative stress, uremia and hyperphosphatemia, "osteoblast-like" cells are formed in the vessel wall and these mineralizing cells play a critical role in the calcification process. ${ }^{3}$ Important transcription factors such as Msx 2, osterix and RUNX2 play an important role in programming osteogenesis, and thus the simultaneous increase in arterial osteochondrocytic programs and decrease in active cellular defense mechanisms creates the "perfect storm" of vascular calcification seen in end-stage renal disease (ESRD). Studies conducted in patients with ESRD showed that calcification in vascular structures is an important component of the atherosclerosis process; a positive linear relationship was observed between the severity of calcification in atherosclerotic lesions in the coronary or cerebral arteries and the frequency of myocardial infarction and stroke. Many bone-associated proteins such as osteocalcin (OC), osteopontin (OPN), osteoprotegerin (OPG) and matrix $\gamma$-carboxyglutamic acid protein (MGP) have been shown to be associated with atherosclerotic calcification and expressed in atherosclerotic plaques. ${ }^{3-5}$ Gla-rich protein (GRP), is a circulating vitamin K-dependent protein (VKDP) with a dual capacity to function as an inhibitor of pathological calcification and anti-inflammatory agent, in the articular and cardiovascular systems. Although GRP has been suggested as a potential marker for vascular calcification. ${ }^{6-10}$

Neutrophil-lymphocyte ratio (NLR), a simple laboratory parameter, has been shown to be associated with cardiovascular diseases and stroke. ${ }^{11}$ It has also been reported that NLR is associated with inflammation and poor prognosis in CKD. ${ }^{12,13}$ Likewise, it has been shown that the platelet-lymphocyte ratio (PLR) is associated with cardiovascular diseases and inflammation. ${ }^{14,15}$ Carotid artery intima media thickness (CIMT), measured by ultrasonographic method, is considered as a non-invasive indicator used to evaluate the presence and extent of atherosclerosis in epidemiological, clinical and observational studies. ${ }^{16}$ To date, current guidelines recommend the use of carotid atherosclerosis in asymptomatic patients at risk, such as CKD. In our study, we investigated the relationship between GLA Rich protein levels, carotid intima media thickness and inflammatory parameters in patients with predialysis stage 3, 4 and 5 CKD.

\section{Materials and Methods Study Subjects}

A total of 106 patients aged $\geq 18$ years with CKD stage 3 , stage 4 and non-dialysis stage 5 were enrolled in the study. This cross-sectional study was conducted in the Health Sciences University Istanbul Kanuni Sultan Suleyman Training and Research Hospital starting from September till December of the year 2020. The study protocol conformed to the Declaration of Helsinki and was approved by the local ethics committees (Health Sciences University Istanbul Kanuni Sultan Suleyman Training and Research Hospital). All participants gave their written informed consent before entering the study. All patients included in the study were previously diagnosed as having CKD according to National Kidney Foundation K/DOQI Guidelines. ${ }^{17}$ Patients with obesity, uncontrolled hypertension, coronary artery disease, with active cancer or liver disease, malignant hematologic disorders, acute renal failure, acute or chronic infections, were excluded. As the control group $(n=25)$; healthy volunteers without any known illness, regular drug use, smoking, alcohol use, and obesity were recruited.

\section{Laboratory Data}

Blood samples were taken after overnight fasting. Biochemical analyses, serum blood urea nitrogen (BUN), creatinine, sodium, potassium, calcium, phosphate, magnesium, uric acid, albümin, complete blood count (CBC), 25-hydroxy vitamin $\mathrm{D}$, parathyroid hormone (PTH) and C-reactive protein (CRP) were conducted according to the standard biochemical procedures. To determine the levels of GRP, serum samples were frozen at $-80^{\circ} \mathrm{C}$ until ELISA tests were performed. ELISA Kits (Bioassay Technology Laboratory, Shanghai Korain Biotech, China) were used and tests carried out on BioTek ELx50 Washer and BioTek ELx800 Absorbance Reader according to manufacturer's 
instructions. Proteinuria was calculated protein/creatinine ratio from a random urine sample to estimate 24-hour protein excretion. Neutrophil-to-lymphocyte ratio (NLR) and the platelet-to-lymphocyte ratio (PLR) were obtained by dividing the absolute neutrophil count by lymphocytes and between platelets and lymphocytes, respectively. Glomerular filtration rate (GFR) values of the patients were calculated with the formula:

CKD-EPI $(\mathrm{GFR}=141 * \min (\mathrm{Scr} / \kappa, 1) \alpha * \max (\mathrm{Scr} / \kappa, 1)$ $1.209 * 0.993$ Age $* 1.018$ [if female] $* 1.159$ [if black]).

\section{Measurement of Carotid Intima Media Thickness}

All subjects were supine and the anterior neck was fully exposed with the head back. Two separate measurements were made on the left common carotid artery and the right common carotid artery $(1 \mathrm{~cm}$ proximal to the bulbus), and the average of these two measurements was taken. No measurements were taken from places where atheroma plaques were visible. CIMT was evaluated between two echogenic lines seen between the intima-lumen interface and the media-adventitia interface. The mean CIMT was calculated by dividing the sum of the right and left CIMT into two. CIMT was measured in the Radiology Outpatient Clinic of Health Sciences University Istanbul Kanuni Sultan Suleyman Training and Research Hospital using the B mode of Mindray DC-7 device. The cut-off value for CIMT $0.90 \mathrm{~mm}^{18}$

\section{Statistical Analysis}

Statistical analyses were performed using the IBM SPSS Statistics for Windows, Version 22.0 Armonk, NY: IBM Corp. The variables were investigated using visual (histograms, probability plots) and analytic methods (Kolmogorov-Smirnov/Shapiro-Wilk's test) to determine whether or not they are normally distributed. Data with normal distribution are given as mean \pm standard deviation (SD), the data whose distribution was not normal were given as median (interquartile range-IQR). After checking the normality distribution of scale variables independent samples were compared with appropriate significance tests (e.g. the MannWhitney $U$-test, Kruskal-Wallis $H$-test). Pearson's chisquare and Fisher's exact test were used for categorical variables where appropriate. The association between variables was determined using correlation analysis.
The Pearson correlation coefficient was used to determine the correlation between variables with normal distribution. For those variables in which non-normal distribution was present, the Spearman coefficient of correlation was applied. The results with $\mathrm{p}<0.05$ were considered statistically significant.

\section{Results}

\section{Demographic and Laboratory Characteristics of the Patients}

A total of 116 patients, 62 (53.4\%) female and 54 (46.6\%) male, were included in the study. The mean age of the patients was $60.1 \pm 13.6$. Of the patients included in the study, 107 (92.2\%) had HT, and 46 (39.7\%) had DM. 49 patients $(42.2 \%)$ had stage 3 CKD, 39 patients $(33.6 \%)$ had stage $4 \mathrm{CKD}$ and 28 (24.1\%) had stage $5 \mathrm{CKD}$. The mean GFR values of the patients were $26.3 \pm 13.7 \mathrm{~mL} /$ min. The mean right CIMT was $0.65 \pm 0.2 \mathrm{~mm}$, the left CIMT was $0.69 \pm 0.2 \mathrm{~mm}$, and the mean CIMT was $0.67 \pm$ $0.2 \mathrm{~mm}$. The average of the demographic and laboratory data of the patients is given in Table 1 . The mean age of the patient group was found to be significantly higher than the healthy control group $(\mathrm{p}=0.001)$. In the comparison of patients according to CKD stages; There was no significant difference between GRP levels and CIMT. A significant difference was found between stage 3 patients and stage 5 patients, and between stage 4 patients and stage 5 patients in terms of NLR values. A significant difference was found between stage 3 patients and stage 5 patients in terms of PLR values.

\section{Evaluation of Multiple Relationships Between GLA Rich Protein and Other Data in Chronic Kidney Patients}

In the comparison of serum GRP levels of patients with demographic and laboratory data: there was no significant difference between age, gender, presence of DM, BUN, creatinine, calcium, phosphorus, magnesium, albumin, proteinuria, hemoglobin $\mathrm{PTH}, \mathrm{CRP}$ and $25 \mathrm{OH}$ vitamin D values and GRP levels. no relationship was found. A positive significant correlation was found between uric acid and CIMTs and GRP (respectively; $\mathrm{r}=0.192, \mathrm{p}=0.039$, $\mathrm{r}=0.277, \mathrm{p}=0.003 ; \mathrm{r}=0.354, \mathrm{p}=0.000 ; \mathrm{r}=0.330, \mathrm{p}=0.000)$.). No correlation was found between GRP levels and NLR and PLR values. 
Table I Baseline Characteristics and Laboratory Parameters of Patients

\begin{tabular}{|c|c|c|}
\hline Parameter & Value & Minimum Maximum \\
\hline GLA Rich Protein ${ }^{\#}$ & $621.8(568.6-733.9)^{\#}$ & |42.4-3078.5 \\
\hline Age (years)* & $60.1 \pm 13.6^{*}$ & $29-82$ \\
\hline Gender (F/M) & $62 / 54$ & \\
\hline$D M$ & $46 / 70$ & \\
\hline HT & $106 / 10$ & \\
\hline GFR $(\mathrm{mL} / \mathrm{dk})^{*}$ & $26.3 \pm 13.7^{*}$ & $4-59$ \\
\hline BUN $(\mathrm{mg} / \mathrm{dl})^{*}$ & $42.5 \pm 19.4^{*}$ & $14-112$ \\
\hline Creatinine $(\mathrm{mg} / \mathrm{dl})^{\#}$ & $2.17(1.74-3.42)^{\#}$ & $1.25-9.77$ \\
\hline Calcium $(\mathrm{mg} / \mathrm{dl})^{*}$ & $9.1 \pm 0.8^{*}$ & $7.1-10.7$ \\
\hline Phosphorus (mg/dl) & $3.8(3.2-4.5)^{\#}$ & $2-8.7$ \\
\hline $\mathrm{Ca} \times \mathrm{P}^{\#}$ & $35.3(29.8-40.6)^{\#}$ & $19-79.2$ \\
\hline Magnesium $(\mathrm{mg} / \mathrm{dl})^{*}$ & $1.94 \pm 0.3^{*}$ & $1.14-2.94$ \\
\hline Uric Acid $(\mathrm{mg} / \mathrm{dl})^{*}$ & $6.3 \pm 1.4^{*}$ & $2.8-10.6$ \\
\hline Albumin $(\mathrm{gr} / \mathrm{dl})^{*}$ & $4.1 \pm 0.4^{*}$ & $2.7-5.6$ \\
\hline Proteinuria (gr/day) & $0.78(0.18-2.56)^{\#}$ & $0.05-8.29$ \\
\hline Hemoglobin (gr/dl)* & $11.5 \pm 2.3^{*}$ & $6.3-17.1$ \\
\hline$N L R^{\#}$ & $2.8(2.3-3.6)$ & $1.2-7.6$ \\
\hline $\mathrm{PLR}^{\#}$ & $129.5(93.2-180.3)$ & $|4.3-53|$ \\
\hline PTH $(p g / m L)^{\#}$ & $97.5(64-193)^{\#}$ & $|4-160|$ \\
\hline $\operatorname{CRP}(\mathrm{mg} / \mathrm{l})^{\#}$ & $2.7(1.3-5.7)^{\#}$ & $0.1-17.8$ \\
\hline $25 \mathrm{OH}$ Vitamin $\mathrm{D}(\mathrm{ng} / \mathrm{mL})^{\#}$ & $16.7(11.8-25.4)^{\#}$ & $4-69.4$ \\
\hline Right CIMT (mm)* & $0.65 \pm 0.2$ & $0.4-1$ \\
\hline Left CIMT $(\mathrm{mm})^{*}$ & $0.69 \pm 0.2$ & $0.4-1.2$ \\
\hline Mean CIMT $(\mathrm{mm})^{*}$ & $0.67 \pm 0.2$ & $0.4-1.1$ \\
\hline
\end{tabular}

Notes: " Data is given Median (IQR), *Data is given Mean \pm SD.

Abbreviations: DM, diabetes mellitus; HT, hypertension; GFR, glomerular filtration rate; BUN, blood urea nitrogen; NLR, neutrophil to lymphocyte ratio; PLR, platelet to lymphocyte ratio; PTH, parathormone; CRP, C-reactive protein; CIMT, carotid intima media thickness.

\section{Evaluation of Multiple Relationships} Between Carotid Intima Media Thickness and Other Data in Chronic Kidney

\section{Patients}

No significant correlation was found between comorbid diseases and GFR values and CIMT thickness. A positive significant relationship was found between male gender and CIMT. There was a positive correlation between right CIMT, left CIMT and mean CIMT, and age and GRP. No significant correlation was found between other laboratory parameters and CIMT. Significant results are given in Table 2. No significant correlation was found between CIMT and NLR, PLR values.

\section{Comparison of Patients According to Median GLA Rich Protein Levels}

The patients were divided into two groups according to the median value of GRP. Patients with GRP levels of 621.8 and above and patients with GRP levels below 621.8 were compared. There was no significant difference between the
Table 2 Evaluation of the Relationships Between CIMT and Other Data

\begin{tabular}{|l|c|c|c|}
\hline & $\begin{array}{c}\text { Right CIMT } \\
(\boldsymbol{r}, \boldsymbol{p})\end{array}$ & $\begin{array}{c}\text { Left CIMT } \\
(\boldsymbol{r}, \boldsymbol{p})\end{array}$ & $\begin{array}{c}\text { Mean CIMT } \\
(\boldsymbol{r}, \boldsymbol{p})\end{array}$ \\
\hline Age (years) & $\begin{array}{c}0.478 \\
<0.001\end{array}$ & $\begin{array}{c}0.393 \\
<0.001\end{array}$ & $\begin{array}{c}0.445 \\
<0.001\end{array}$ \\
\hline Gender (Male) & 0.203 & 0.237 & 0.223 \\
$*$ & 0.029 & 0.010 & 0.016 \\
\hline DM* $^{*}$ & 0.140 & 0.123 & 0.133 \\
& 0.134 & 0.188 & 0.155 \\
\hline HT* & -0.057 & -0.032 & -0.037 \\
& 0.544 & 0.737 & 0.691 \\
\hline GFR (mL/dk) & 0.058 & 0.060 & 0.061 \\
& 0.537 & 0.519 & 0.513 \\
\hline GLA Rich $^{\#}$ & 0.277 & 0.354 & 0.330 \\
protein $^{\#}$ & 0.003 & $<0.001$ & $<0.001$ \\
\hline Potassium & 0.258 & 0.188 & 0.227 \\
(mEq/l) $^{\#}$ & 0.005 & 0.043 & 0.014 \\
\hline
\end{tabular}

Notes: *Spearman Correlation analysis, "Pearson Correlation analysis. Abbreviations: DM, diabetes mellitus; HT, hypertension; GFR, glomerular filtration rate; CIMT, carotid intima media thickness. 
groups in terms of age, gender and comorbid diseases. Looking at the laboratory parameters. While significantly higher proteinuria was detected in patients with high GRP levels, no difference was found in terms of other parameters. Comparative data of the two groups are given in Table 3.

\section{Comparison of Patients According to CIMT}

Patients were divided into two groups as those with CIMT below $0.90 \mathrm{~mm}$ and those with CIMT $0.90 \mathrm{~mm}$ and above. Although the mean age of the group with high CIMT was higher than the other group, this difference was not significant. CIMT of male patients was found to be significantly higher than female patients $(p=0.010)$. There was no significant difference between the two groups in terms of the presence of HT and DM. While the CRP values of the group with high CIMT were found to be significantly higher $(p=0.005)$, the GRP levels of this group were found to be significantly higher $(p=0.019)$. Comparative data of the two groups are given in Table 4.

\section{Discussion}

In our study, we examined the relationship between CIMT and GRP levels and the relationship between GRP levels and inflammatory parameters in patients with stage 3, stage 4 and stage $5 \mathrm{CKD}$ disease. As it is known, early and rapidly developing atherosclerosis, cardiovascular and cerebrovascular diseases due to this developing atherosclerosis are the most important causes of mortality and morbidity in CKD. This high mortality rate is not unique to advanced kidney disease. Even patients with mild-tomoderate chronic kidney disease are faced with the risk of losing their lives in this process, much greater than the chance of progression of kidney disease and dialysis treatment becoming mandatory. In their study in which they followed 27,998 CKD patients, Keith et al reported that the progression of the disease and the development of ESRD and the need for dialysis were reported in $1.1 \%$, $1.3 \%$, and $19.9 \%$, respectively, during the five-year observation period; on the other hand, they showed that the loss of life was $19.5 \%, 24.3 \%$, and $45.7 \%$ in the same period. ${ }^{19}$

Table 3 Comparison of Patients According to Median GLA Rich Protein Levels

\begin{tabular}{|c|c|c|c|}
\hline & GLA Rich Protein < $621.8(n=57)$ & GLA Rich Protein $\geq 621.8(n=59)$ & $\mathbf{p}$ \\
\hline GLA Rich Protein & $567.3(506.3-593.9)$ & $733.4(659.5-829.3)$ & $<0.001$ \\
\hline Age (years)* & $59.8 \pm 13.8$ & $60.4 \pm 13.4$ & 0.842 \\
\hline Gender (F/M) & $31 / 26$ & $31 / 28$ & 0.842 \\
\hline$D M$ & $25 / 32$ & $21 / 38$ & 0.363 \\
\hline$H T$ & $55 / 2$ & $51 / 8$ & 0.054 \\
\hline GFR $(\mathrm{mL} / \mathrm{dk})^{*}$ & $24.4 \pm 14.2$ & $28.2 \pm 13$ & 0.129 \\
\hline BUN $(\mathrm{mg} / \mathrm{dl})^{*}$ & $46.2 \pm 22.3$ & $38.9 \pm 15.4$ & 0.112 \\
\hline Creatinine $(\mathrm{mg} / \mathrm{dl})^{\#}$ & $2.38(1.75-4.39)$ & $2.03(1.63-3.29)$ & 0.081 \\
\hline Calcium (mg/dl) & $9.1 \pm 0.8$ & $9.2 \pm 0.7$ & 0.646 \\
\hline Phosphorus $(\mathrm{mg} / \mathrm{dl})^{\#}$ & $3.9(3.2-4.6)$ & $3.5(3.2-4.4)$ & 0.276 \\
\hline $\mathrm{Ca} \times \mathrm{P}^{\#}$ & $36.1(30.7-40.8)$ & $33.3(27.9-40)$ & 0.383 \\
\hline Magnesium $(\mathrm{mg} / \mathrm{dl})^{*}$ & $1.9 \pm 0.3$ & $1.98 \pm 0.3$ & 0.300 \\
\hline Uric Acid (mg/dl)* & $6.5 \pm 1.4$ & $6.1 \pm 1.5$ & 0.210 \\
\hline Albumin (gr/dl)* & $4.1 \pm 0.4$ & $4.1 \pm 0.4$ & 0.844 \\
\hline Proteinuria (gr/day) ${ }^{\#}$ & $0.44(0.14-1.92)$ & $1.54(0.4-2.64)$ & 0.019 \\
\hline Hemoglobin (gr/dl) & $11.5 \pm 2.7$ & $11.5 \pm 1.8$ & 0.963 \\
\hline $\mathrm{NLR}^{\#}$ & $2.9(2.5-3.8)$ & $2.7(2.1-3.4)$ & 0.068 \\
\hline $\mathrm{PLR}^{\#}$ & $137.9(93.2-205.5)$ & $123(92.6-159)$ & 0.256 \\
\hline PTH $(p g / m L)^{\#}$ & 101 (74-259) & $97(59-147)$ & 0.191 \\
\hline $\operatorname{CRP}(\mathrm{mg} / \mathrm{l})^{\#}$ & $2.5(1.4-5.3)$ & $3(1.2-6.4)$ & 0.631 \\
\hline $25 \mathrm{OH}$ Vitamin $\mathrm{D}(\mathrm{ng} / \mathrm{mL})^{\#}$ & $16.1(11.5-24.6)$ & $16.9(11.7-25.5)$ & 0.581 \\
\hline Right CIMT (mm)* & $0.63 \pm 0.15$ & $0.67 \pm 0.18$ & 0.250 \\
\hline Left CIMT $(\mathrm{mm})^{*}$ & $0.65 \pm 0.18$ & $0.73 \pm 0.23$ & 0.081 \\
\hline Mean CIMT $(\mathrm{mm})^{*}$ & $0.64 \pm 0.16$ & $0.70 \pm 0.20$ & 0.114 \\
\hline
\end{tabular}

Notes: \# Data is given Median (IQR), *Data is given Mean \pm SD. Italicized value indicates statistically significant.

Abbreviations: DM, diabetes mellitus; HT, hypertension; GFR, glomerular filtration rate; BUN, blood urea nitrogen; NLR, neutrophil to lymphocyte ratio; PLR, platelet to lymphocyte ratio; PTH, parathormone; CRP, C-reactive protein; CIMT, carotid intima media thickness. 
Table 4 Comparison of Patients According to CIMT

\begin{tabular}{|c|c|c|c|}
\hline & CIMT $<0.90 \mathrm{~mm}(n=86)$ & CIMT $\geq 0.90 \mathrm{~mm} \quad(n=30)$ & $\mathbf{p}$ \\
\hline Age (years)* & $59.9 \pm 14.2$ & $63.5 \pm 10.8$ & 0.148 \\
\hline Gender (F/M) & $52 / 34$ & $10 / 20$ & 0.010 \\
\hline$D M$ & $35 / 51$ & $11 / 19$ & 0.698 \\
\hline HT & $80 / 6$ & $26 / 4$ & 0.280 \\
\hline GFR $(\mathrm{mL} / \mathrm{dk})^{*}$ & $25.2 \pm 14.2$ & $29.5 \pm 11.6$ & 0.124 \\
\hline BUN $(\mathrm{mg} / \mathrm{dl})^{*}$ & $42.4 \pm 21$ & $42.8 \pm 14.2$ & 0.372 \\
\hline Creatinine $(\mathrm{mg} / \mathrm{dl})^{\#}$ & $2.34(1.74-4.09)$ & $1.9(1.76-3.12)$ & 0.149 \\
\hline Calcium (mg/dl) & $9 \pm 0.8$ & $9.4 \pm 0.7$ & 0.174 \\
\hline Phosphorus (mg/dl) & $3.9(3.2-4.6)$ & $3.6(3.2-4.2)$ & 0.487 \\
\hline $\mathrm{Ca} \times \mathrm{P}^{\#}$ & $35.2(29.3-40.8)$ & $35.7(30.7-40.8)$ & 0.955 \\
\hline Magnesium (mg/dl)* & $2 \pm 0.3$ & $1.9 \pm 0.3$ & 0.232 \\
\hline Uric Acid $(\mathrm{mg} / \mathrm{dl})^{*}$ & $6.3 \pm 1.4$ & $6.3 \pm 1.5$ & 0.927 \\
\hline Albumin $(\mathrm{gr} / \mathrm{dl})^{*}$ & $4.1 \pm 0.5$ & $4.1 \pm 0.3$ & 0.829 \\
\hline Proteinuria (gr/day) $)^{\#}$ & $0.44(0.15-1.86)$ & I.I (0.2-2.93) & 0.147 \\
\hline Hemoglobin (gr/dl)* & $11.3 \pm 2.4$ & $11.9 \pm 1.9$ & 0.142 \\
\hline$N L R^{\#}$ & $2.8(2.3-3.9)$ & $2.7(2.2-3.4)$ & 0.346 \\
\hline $\mathrm{PLR}^{\#}$ & $123(95.1-177.8)$ & $135.5(86.4-198)$ & 0.791 \\
\hline PTH $(p g / m L))^{\#}$ & $100(63-294)$ & $96(78-117)$ & 0.369 \\
\hline $\operatorname{CRP}(\mathrm{mg} / \mathrm{l})^{\#}$ & $2(1.18-4.9)$ & $4.6(3-9.3)$ & 0.005 \\
\hline $25 \mathrm{OH}$ Vitamin $\mathrm{D}(\mathrm{ng} / \mathrm{mL})^{\#}$ & $16.6(11.8-25.4)$ & $16.5(9.5-25.5)$ & 0.592 \\
\hline GLA Rich Protein ${ }^{\#}$ & $607.9(562.4-727.6)$ & 643.6 (593.9-1084.7) & 0.019 \\
\hline
\end{tabular}

Notes: " Data is given Median (IQR), *Data is given Mean \pm SD. Italicized value indicates statistically significant.

Abbreviations: DM, diabetes mellitus; HT, hypertension; GFR, glomerular filtration rate; BUN, blood urea nitrogen; NLR, neutrophil to lymphocyte ratio; PLR, platelet to lymphocyte ratio; PTH, parathormone; CRP, C-reactive protein; CIMT, carotid intima media thickness.

For this reason, early detection of cardiovascular disease risk and taking precautions for it are of great importance in reducing mortality. CIMT measured by ultrasonographic methods is considered as an inexpensive, easily applied, reproducible, non-invasive indicator used to evaluate the presence and extent of atherosclerosis in epidemiological, clinical and observational studies. ${ }^{20}$ Coronary angiography provides information about lesions in the arterial lumen. However, with CIMT measurement, it can be evaluated even at an early stage when anatomical stenosis has not yet occurred and the disorder is limited only to the vessel wall. The fact that CIMT evaluation differences are quite low in evaluations made by the same observer at different times and by different observers increases its reliability as an atherosclerosis risk indicator. Studies have shown that an increase in CIMT increases the risk of coronary events and related death. $^{21-23}$ In our study; CIMT thicknesses of patients with DM and HT diagnosis without known coronary artery disease were found to be significantly higher than the control group. We detected CIMT of approximately one-fourth (25.8\%) of the patients above $0.90 \mathrm{~mm}$, which is the atherosclerosis margin. While the mean age of the patients was found to be significantly higher than the control group, there was no significant difference between the mean age of patients with high and low CIMT. In addition, no difference was found between these patients in terms of comorbid diseases. In addition to all these, the CIMT of the patients was found to be significantly higher than the male patients.

In studies conducted in patients with CKD and ESRD, it was found that calcification observed in vascular structures emerged as an important component of the atheroarteriolosclerosis process. It has been observed that there is a positive linear relationship between the severity of calcification in atherosclerotic lesions in the coronary or cerebral arteries, the frequency of myocardial infarction and stroke, and the increased morbidity observed during the disease process. Vascular calcification, which can be defined as calcium phosphate deposition in the arterial wall in the form of bioapatite similar to that in bone. It is a clinical condition that is frequently seen in diseases with endothelial damage such as CKD, DM, HT, atherosclerosis, and leads to increased morbidity and mortality even at young ages. ${ }^{24-27}$ Kramer et al found that vascular calcification was increased in CKD patients with stage 3-5 CKD between the ages of 30-65 years compared to the 
healthy population, and vascular calcification was higher in diabetic CKD patients compared to non-diabetic patients. $^{28}$ The mechanism of vascular calcification in terms of being easy to understand. Activation of osteogenesis in the vessel wall, deficiency of factors preventing calcification, increased bone turnover and disorders in mineral metabolism. These specific calcium regulatory proteins such as fetuin-A, MGP, and OPG act as calcification inhibitors with local and systemic effects and play an important role in the development and prevention of uremic vascular calcification. Coronary artery calcification resulting from vascular calcification causes conduction defects, arrhythmia and myocardial fibrosis. In addition, it has been shown that the decrease of Fetuin A, MGP, OPG and osteopontin (OPN) in CKD contribute to the increase of vascular calcification. ${ }^{28-30}$ Another vascular calcification-related protein that has come to the fore in recent years is GRP. GRP, also known as upper zone of growth plate and cartilage matrix associated protein (UCMA), is the newest member of the VKDPs family recently shown to be involved in the crosstalk between inflammation and calcification of articular tissues in osteoarthritis. ${ }^{7}$ It has been shown in some studies that GRP has a function in calcium homeostasis in the cardiovascular system, most likely by acting as a calcification inhibitor through its calcium chelator and mineral-binding capacity, and involvement in the mineralization competence of vascular smooth muscle cell derived extracellular vesicles. ${ }^{6}$ Silva et al showed that GRP is associated with vascular damage in a study conducted in diabetic patients with CKD. ${ }^{10}$

Inflammation and the inflammatory response to it emerge as an important factor in the pathogenesis and progression of atherosclerosis. Inflammatory mediators secreted by neutrophils play a role in the damage of the vessel wall, while lymphocytes take part in the regulation of the inflammatory response. In cases where inflammation persists, lymphocyte counts decrease due to increased lymphocyte apoptosis. Lymphocytes represent a more favorable immune response, while neutrophils cause a destructive inflammatory reaction. In addition, ongoing inflammatory conditions lead to increased proliferation and relative thrombocytosis in the megakaryocytic lineages. Therefore, these inflammatory parameters such as NLR and PLR, which are simple, inexpensive and easily calculated, were thought to be used as biomarkers and were supported by studies. In a meta-analysis by Angkananard et al, it was shown that high NLR is associated with cardiocerebrovascular diseases such as coronary artery disease, acute coronary syndrome and stroke. ${ }^{11}$ In another study by Okyay and colleagues, it was shown that high NLR was associated with inflammation in patients with CKD. ${ }^{12}$ In a study by Yüksel et al, it was shown that high PLR may contribute to traditional risk factors in predicting severe atherosclerosis. $^{15}$ In a study by Viegas et al, it was suggested that GRP acts as a new molecular mediator linking events in pathologies related to chronic inflammation and calcification. ${ }^{8}$ In our study, it was determined that there was a positive correlation between GRP levels and CIMT in patients with predialysis CKD, and GRP levels were higher in patients with CIMT above $0.90 \mathrm{~mm}$. However, no correlation was found between parameters such as CRP, NLR and PLR, which are considered to be parameters associated with inflammation, and GRP levels. However, CRP levels were found to be high in patients with high CIMT as expected. The small number of our cases, the significant age difference between the control group and the patient group, and the exclusion of patients with coronary artery disease are the limitations of our study. However, beyond all this, we could not find any other study in the literature showing the relationship between CIMT and GRP levels in patients with CKD. This seems to be the strength of our study. All these findings suggest that GRP levels can be used as a cardiovascular event biomarker in patients with CKD. Multicenter studies with more cases are needed on this subject.

\section{Disclosure}

The authors report no conflicts of interest in this work.

\section{References}

1. Kendrick J, Chonchol MB. Nontraditional risk factors for cardiovascular disease in patients with chronic kidney disease. Nat Clin Pract Nephrol. 2008;4(12):672-681. doi:10.1038/ncpneph0954

2. Sarnak MJ, Coronado BE, Greene T, et al. Cardiovascular disease risk factors in chronic renal insufficiency. Clin Nephrol. 2002;57 (05):327-335. doi:10.5414/CNP57327

3. Mizobuchi M, Towler D, Slatopolsky E. Vascular calcification: the killer of patients with chronic kidney disease. $J$ Am Soc Nephrol. 2009;20(7):1453-1464. doi:10.1681/ASN.2008070692

4. Hirota S, Imakita M, Kohri K, et al. Expression of osteopontin messenger RNA by macrophages in atherosclerotic plaques. A possible association with calcification. Am J Pathol. 1993;143(4):1003-1008.

5. Dhore CR, Cleutjens JPM, Lutgens E, et al. Differential expression of bone matrix regulatory proteins in human atherosclerotic plaques. Arterioscler Thromb Vasc Biol. 2001;21(12):1998-2003. doi:10.1161/ hq1201.100229 
6. Viegas CSB, Rafael MS, Enriquez JL, et al. Gla-rich protein acts as a calcification inhibitor in the human cardiovascular system. Arterioscler Thromb Vasc Biol. 2015;35(2):399-408. doi:10.1161/ ATVBAHA.114.304823

7. Cavaco S, Viegas CSB, Rafael MS, et al. Gla-rich protein is involved in the cross-talk between calcification and inflammation in osteoarthritis. Cell Mol Life Sci. 2016;73(5):1051-1065. doi:10.1007/s00018-015-2033-9

8. Viegas CSB, Costa RM, Santos L, et al. Gla-rich protein function as an anti-inflammatory agent in monocytes/macrophages: implications for calcification-related chronic inflammatory diseases. PLoS One. 2017;12(5):1-23. doi:10.1371/journal.pone.0177829

9. Viegas CSB, Santos L, Macedo AL, et al. Chronic kidney disease circulating calciprotein particles and extracellular vesicles promote vascular calcification: a role for GRP (Gla-Rich Protein). Arterioscler Thromb Vasc Biol. 2018;38(3):575-587. doi:10.1161/ATVBAHA.1 17.310578

10. Silva AP, Viegas CSB, Mendes F, et al. Gla-Rich Protein (GRP) as an early and novel marker of vascular calcification and kidney dysfunction in diabetic patients with CKD: a Pilot Cross-Sectional Study. J Clin Med. 2020;9(3):635. doi:10.3390/jcm9030635

11. Angkananard T, Anothaisintawee T, McEvoy M, Attia J, Thakkinstian A. Neutrophil lymphocyte ratio and cardiovascular disease risk: a Systematic Review and Meta-Analysis. Biomed Res Int. 2018;2018:1-11. doi:10.1155/2018/2703518

12. Okyay GU, Inal S, Öneç K, et al. Neutrophil to lymphocyte ratio in evaluation of inflammation in patients with chronic kidney disease. Ren Fail. 2013;35(1):29-36. doi:10.3109/0886022X.2012.734429

13. Yoshitomi R, Nakayama M, Sakoh T, et al. High neutrophil/lymphocyte ratio is associated with poor renal outcomes in Japanese patients with chronic kidney disease. Ren Fail. 2019;41(1):238-243. doi:10.1080/0886022X.2019.1595645

14. Ye GL, Chen Q, Chen X, et al. The prognostic role of platelet-tolymphocyte ratio in patients with acute heart failure: a cohort study. Sci Rep. 2019;9(1):1-8. doi:10.1038/s41598-019-47143-2

15. Yüksel M, Yıldız A, Oylumlu M, et al. The association between platelet/lymphocyte ratio and coronary artery disease severity. Anatol J Cardiol. 2015;15(8):640-647. doi:10.5152/akd.2014.5565

16. Kim JK, Song YR, Kim MG, Kim HJ, Kim SG. Clinical significance of subclinical carotid atherosclerosis and its relationship with echocardiographic parameters in non-diabetic chronic kidney disease patients. BMC Cardiovasc Disord. 2013;13(1):1-10. doi:10.1186/ 1471-2261-13-96

17. Eckardt KU, Kasiske BL, Abboud O, et al. Foreword. Kidney Int. 2009;76(SUPPL. 113):S1-S130. doi:10.1038/ki.2009.188

18. Simova I, Katova T, Denchev S. Diagnostic accuracy of flow-mediated dilatation and intima-media thickness for the presence of significant coronary artery disease. J Am Soc Hypertens. 2009;3 (6):388-394. doi:10.1016/J.JASH.2009.09.003

International Journal of General Medicine

\section{Publish your work in this journal}

The International Journal of General Medicine is an international, peer-reviewed open-access journal that focuses on general and internal medicine, pathogenesis, epidemiology, diagnosis, monitoring and treatment protocols. The journal is characterized by the rapid reporting of reviews, original research and clinical studies
19. Keith DS, Nichols GA, Gullion CM, Brown JB, Smith DH. Longitudinal follow-up and outcomes among a population with chronic kidney disease in a large managed care organization. Arch Intern Med. 2004;164(6):659. doi:10.1001/archinte.164.6.659

20. Geroulakos G, O'Gorman DJ, Kalodiki E, Sheridan DJ, Nicolaides AN. The carotid intima-media thickness as a marker of the presence of severe symptomatic coronary artery disease. Eur Heart J. 1994;15(6):781-785. doi:10.1093/oxfordjournals.eurheartj. a060585

21. Vanholder R, Massy Z, Argiles A, et al. Chronic kidney disease as cause of cardiovascular morbidity and mortality. Nephrol Dial Transplant. 2005;20(6):1048-1056. doi:10.1093/ndt/gfh813

22. Baldassarre D, Amato M, Bondioli A, Sirtori CR, Tremoli E. Carotid artery intima-media thickness measured by ultrasonography in normal clinical practice correlates well with atherosclerosis risk factors. Stroke. 2000;31(10):2426-2430. doi:10.1161/01.STR.31.10.2426

23. Makita S, Abiko A, Naganuma Y, Nagai M, Nakamura M. Chronic kidney disease is associated with increased carotid artery stiffness without morphological changes in participants of health check-up programs. Atherosclerosis. 2010;213(1):306-310. doi:10.1016/j. atherosclerosis.2010.08.057

24. Suliman ME, García-López E, Anderstam B, Lindholm B, Stenvinkel P. Chapter 6 Vascular calcification inhibitors in relation to cardiovascular disease with special emphasis on Fetuin-A in chronic kidney disease. Adv Clin Chem. 2008;46:217-262. doi:10.1016/S0065-2423(08)00406-X

25. Ketteler M, Westenfeld R, Schlieper G, Brandenburg V. Pathogenesis of vascular calcification in dialysis patients. Clin Exp Nephrol. 2005;9(4):265-270. doi:10.1007/s10157-005-0385-4

26. London GM. Cardiovascular calcifications in uremic patients: clinical impact on cardiovascular function. J Am Soc Nephrol. 2003;14(suppl 4):S305-S309. doi:10.1097/01.asn.0000081664.65772.eb

27. Proudfoot D, Skepper JN, Shanahan CM, Weissberg PL. Calcification of human vascular cells in vitro is correlated with high levels of matrix Gla protein and low levels of osteopontin expression. Arterioscler Thromb Vasc Biol. 1998;18(3):379-388. doi:10.1161/ 01.ATV.18.3.379

28. Kramer H, Toto R, Peshock R, Cooper R, Victor R. Association between chronic kidney disease and coronary artery calcification: the Dallas heart study. J Am Soc Nephrol. 2005;16(2):507-513. doi:10.1681/ASN.2004070610

29. Derici U, El Nahas AM. Vascular calcifications in uremia: old concepts and new insights. Semin Dial. 2006;19(1):60-68. doi:10.1111/ j.1525-139X.2006.00120.x

30. Dellegrottaglie S, Sanz J, Rajagopalan S. Molecular determinants of vascular calcification: a bench to bedside view. Curr Mol Med. 2006;6(5):515-524. doi:10.2174/156652406778018653 across all disease areas. The manuscript management system is completely online and includes a very quick and fair peer-review system, which is all easy to use. Visit http://www.dovepress.com/ testimonials.php to read real quotes from published authors. 